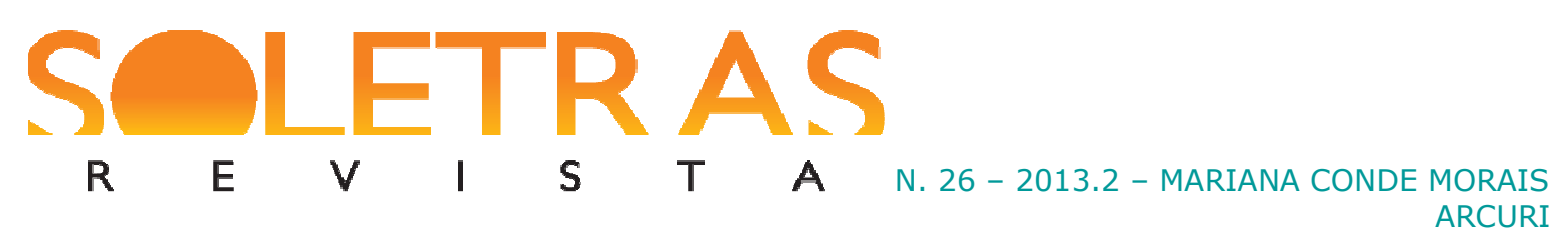

\title{
Literatura em quadrinhos hoje
}

\author{
Mariana Conde Moraes Arcuri ${ }^{1}$ \\ Universidade Federal do Estado do Rio de Janeiro
}

Resumo: A fim de que o público perceba os quadrinhos como estética independente, com noções e códigos peculiares, e se familiarize com ela, é essencial que o gênero seja encarado como objeto de leitura em si, e não uma espécie de ponte para se atingir outro nível, pretensamente mais rebuscado, de leitura. Este trabalho busca mostrar como, ao se definir como linguagem livre, os quadrinhos encontram em sua própria constituição o seu refinamento. Com o propósito de difundir a gramática especial dos quadrinhos, urge formar leitores habituados ao gênero. O percurso, porém, é tortuoso. Visto quase não haver pesquisas acadêmicas aprofundadas sobre o tema, procurou-se recorrer à própria história dos quadrinhos, a depoimentos de profissionais da área, como modo de formar uma base teórica consistente. Raramente quadrinhos são trabalhados na escola, e, quando o são, geralmente surgem em livros didáticos como paradigmas de erro, de desvio da norma culta da língua. Além desse caso, por vezes os quadrinhos desempenham o papel de mero adorno ilustrativo, sem terem sua linguagem esmiuçada, sem receberem uma análise densa de seu grau de sofisticação, tão conjugável a outros campos do conhecimento. Como tentativa de reparar esse quadro é que se erige este trabalho.

Palavras-chave: História em quadrinhos. Literatura contemporânea. Mercado editorial. Formação de leitores.

Há cerca de seis anos, por volta de 2007, o mercado editorial brasileiro sofreu uma mudança significativa. À semelhança de São Paulo, o Rio de Janeiro começou a testemunhar o crescimento, em suas livrarias, de setor particular, com a chegada de um volume maciço de material novo de que muitos livreiros e leitores não se ocupavam, em grande parte devido a um total desconhecimento do mesmo. Somente o público consumidor de literatura e cultura marcadamente pop - que muitas vezes se confunde com aquele que frequenta livrarias e eventos culturais - e livreiros mais atentos a novas linguagens perceberam o reaparecimento triunfal dos quadrinhos em cena.

Com uma produção fresca e revigorada tomando as prateleiras das livrarias, muitos leitores começaram a dedicar-se aos quadrinhos, inteirando-se dos lançamentos e aprofundando o contato com essa peculiar parcela do mercado editorial nacional. Nesses seis anos, de acordo com a opinião de leitores, editores e livreiros revelada em entrevistas, parece

\footnotetext{
${ }^{1}$ Doutoranda em Letras Vernáculas - Literatura Brasileira pela UFRJ e mestre em Letras Vernáculas pela mesma instituição. Graduada em Comunicação Social - Jornalismo pela UFRJ. Atua como editora, redatora e copidesque freelance. E-mail: mariarcuri@ yahoo.com.br.
} 


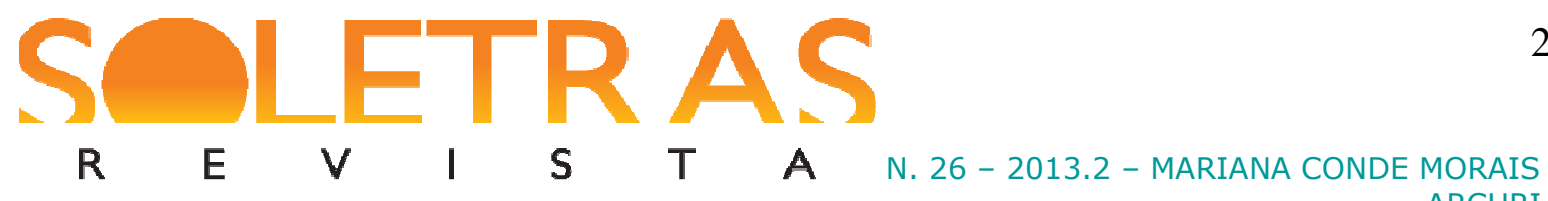

que o interesse do público aumentou, bem como a quantidade de publicações do gênero. Este é um momento dourado para os quadrinhos, em que reportagens em jornais, na Internet e na TV contemplam generosamente o Olimpo vivido pelo setor. Esquecidos durante décadas depois de períodos de larga aceitação junto ao público - mas por vezes não tão larga junto a livrarias e editoras - os quadrinhos, definitivamente, estão na moda. Mesmo editoras grandes, fortes no mercado formal, adaptaram-se a fim de entender os quadrinhos, buscá-los na Internet e incorporá-los a seus catálogos.

Esse quadro é visto com bons olhos por todos os envolvidos no processo de produção, circulação e consumo dos quadrinhos: o artista sente-se privilegiado e vê garantido seu mercado de trabalho; o editor tem a chance de investir em um gênero em ebulição e diversificar o catálogo; o livreiro vê seu público ampliar-se e trazer novas demandas; o professor depara-se com possibilidades de estudo em sala de aula antes impensadas; e o leitor expande sua sensibilidade ao entrar em contato com uma nova experiência, uma linguagem até então pouco usual.

Em termos quantitativos, nunca se publicou tanto do gênero no Brasil. Apenas no final da década de 1970 e início dos anos 1980 os quadrinhos roçaram tamanho nível de popularidade. Contudo, nessa época os quadrinhos eram publicados em formato voltado para bancas de jornal, a exemplo das inúmeras histórias de horror e aventura vendidas diretamente em bancas. Nomes importantes do período são os de Flavio Colin e Julio Shimamoto, ambos dedicados aos quadrinhos de terror. Logo após a explosão de vendas em bancas de jornal, alguns quadrinhos foram acolhidos pela Editora Brasil-América, que, assim, logrou marcar o aparecimento do gênero no seio do mercado editorial brasileiro.

Após esse momento profícuo, os quadrinhos caíram no ostracismo, como observado pelos agentes do gênero - editores, livreiros, autores, leitores. ${ }^{2}$ A produção em larga escala, sistematizada e voltada para um público leitor devotado, cessou. Os quadrinhos, no entanto, continuaram a ser publicados de maneira independente, isto é, desvinculados do mercado editorial. À margem da engrenagem industrial de produção de livros, os quadrinhos sobreviveram como manifestação de uma cultura underground, feitos por e para um público muito específico. Configurou-se, pois, como uma cultura de nicho, cujas publicações e eventos eram compartilhados apenas pelos iniciados; para ter acesso aos quadrinhos, era

\footnotetext{
${ }^{2}$ Baseamo-nos aqui em entrevistas com tais agentes, posto não haver quantidade de material crítico e/ou acadêmico retratando essa mudança no quadro de produção e recepção dos quadrinhos.
} 


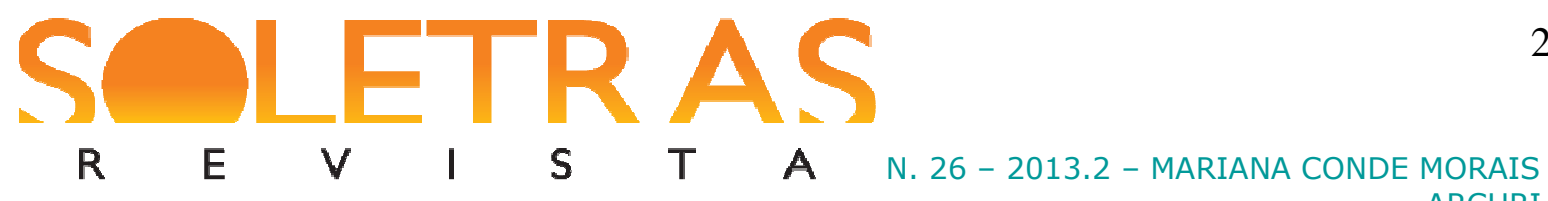

preciso se especializar, procurar os círculos em que fossem divulgados. Quadrinhos não eram comentados e não estavam na grande mídia, em boletins ou clippings - e apenas hoje começam a estar, incentivados pela popularidade que os alçou à condição de meio instigante e hipercontemporâneo. Como afirmou Alzira Valéria Monteiro, produtora executiva da Toscographics, produtora do quadrinista Allan Sieber, "Quadrinhos não saem no PublishNews" (MONTEIRO, 2011) ${ }^{3}$.

A fim de ler a respeito de quadrinhos é necessário visitar redes fora da mídia institucionalizada: sites, blogs e fóruns específicos. Neles é possível encontrar lançamentos e programação de lançamentos, os títulos mais lidos entre os aficionados, as publicações recémsaídas no exterior, as opiniões dos leitores e debates acalorados sobre o gênero. Fóruns e blogs funcionam como uma espécie de termômetro do interesse do leitor e local privilegiado de discussão e divulgação de palestras, lançamentos e encontros. O público consumidor de quadrinhos, ainda fiel a suas raízes de outsider, não se encontra primordialmente nos veículos tradicionais, daí a escolha por caminhos alternativos como Twitter e Facebook.

Mesmo despegados da grande mídia, os quadrinhos conseguem manter intacto seu espaço de circulação e difusão. Prova disso é o sucesso obtido pelo evento Comic-Con no Brasil. A Comic-Con é uma célebre convenção de quadrinhos cuja edição mundial ocorre em San Diego, Estados Unidos, e fez sua estreia em terras brasileiras na Estação Leopoldina, no Rio de Janeiro. Estimulado pela presença de consagrados nomes nacionais e internacionais, como Milo Manara, e pela exposição de grande quantidade de material independente - uma das marcas da Comic-Con é valorizar a originalidade do trabalho independente -, o público compareceu em peso, para surpresa de produtores, curadores e artistas. Por conta do impactante retorno do público, os veículos tradicionais acabaram sendo atraídos para o evento. Nesse caso - aliás, bastante ilustrativo das relações entre quadrinhos e grande mídia -, o interesse dos meios de comunicação não condicionou o triunfo da convenção, pelo contrário, o sucesso da Rio Comic-Con é que seduziu a mídia. Estiveram na Rio Comic-Con, entre outros, a Rede Globo de TV, o jornal $O$ Globo e a MTV.

Ao lado da consolidação dos quadrinhos como estética independente, repleta de descobertas e novas possibilidades, permanece certa dificuldade do gênero de se inserir no mercado editorial comercialmente estabelecido e de ser reconhecido como linguagem

\footnotetext{
${ }^{3}$ Portal de notícias sobre o mercado editorial.
} 


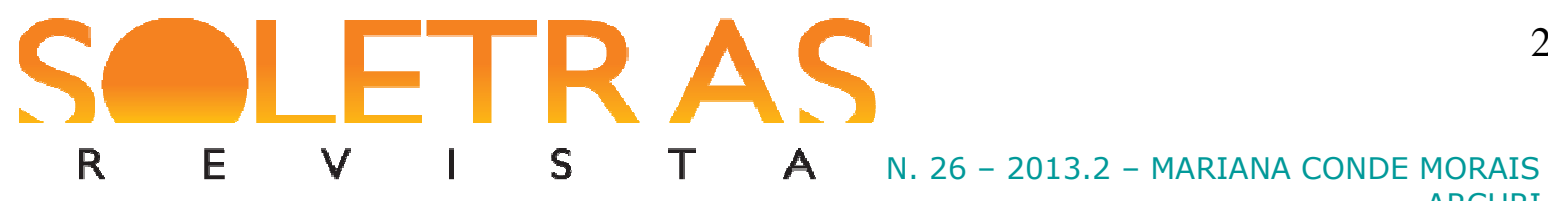

autônoma. No presente, contribuindo para uma dicotomia, duas vertentes são trilhadas concomitantemente: a da afirmação, levada a cabo junto ao grande público, com os quadrinhos descolando-se aos poucos da imagem underground; e, nesse mesmo grande público, a permanência de uma incompreensão acerca do universo particular dos quadrinhos.

Embora exista uma tentativa bem-sucedida de mostrar ao público médio que os quadrinhos constituem uma linguagem de arte própria, a ignorância persiste. O desconhecimento da condição autônoma dos quadrinhos muitas vezes faz com que o próprio artista e o mediador que leva o trabalho até o grande público - o editor e, mais adiante, o livreiro - apresentem os quadrinhos de forma equivocada, seja na formulação e abordagem do conteúdo, seja no tratamento editorial do material, seja na escolha e posicionamento dos pontos de venda. No caso de obras literárias, fazer uma adaptação não consiste tão-somente, ao contrário do que muitos pensam, em elaborar desenhos e balões de diálogo; exige-se, sobretudo, um trabalho de roteiro, que precisa ser bem executado. Flávio Moreira da Costa afirma acerca da adaptação de $O$ alienista, de Machado de Assis, feita pelos premiados irmãos Fábio Moon e Gabriel Bá e publicada pela Agir, do grupo Ediouro:

[...] e agora ei-la [a trama] em história em quadrinhos [...]. Não seria isto uma prova de seu potencial narrativo, do encanto que a própria história contém e que atinge todos nós, leitores e espectadores?

[...] Os gêmeos [Moon e Bá] deixam aqui sua comprovada admiração, transcriando, intercriando, recriando - que é tudo uma forma de criar/homenagear a história "aloprada" de Simão Bacamarte. [...] veja/leia esta homenagem que os irmãos prestam ao nosso gênio (COSTA, 2007, pp. 5-7). (Grifos meus).

A fim de que o público perceba os quadrinhos como estética independente, com noções e códigos peculiares, e se familiarize com ela, é essencial que o gênero seja encarado como objeto de leitura em si, e não uma espécie de ponte para se atingir outro nível, pretensamente mais rebuscado, de leitura. Como linguagem autônoma, os quadrinhos encontram em sua própria constituição o seu refinamento. Com o propósito de difundir a gramática especial dos quadrinhos, urge formar leitores habituados ao gênero. E há melhor caminho que a sala de aula? O percurso, porém, é tortuoso. Raramente quadrinhos são trabalhados na escola, e, quando o são, geralmente surgem em livros didáticos como paradigmas de erro, de desvio da norma culta da língua. Além desse caso, por vezes os quadrinhos desempenham o papel de 


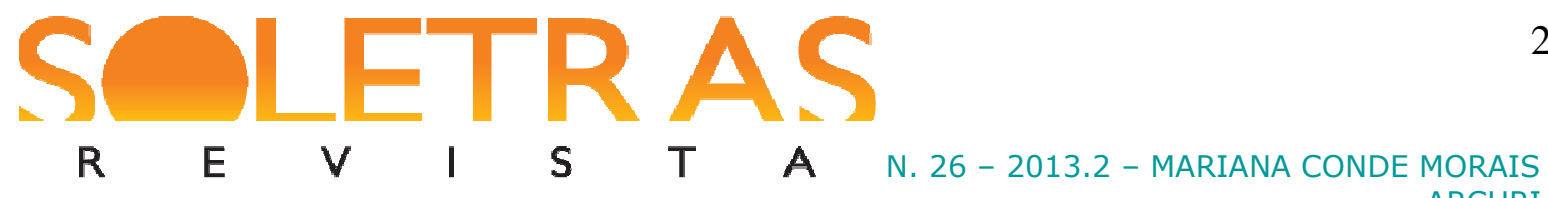

mero adorno ilustrativo, sem terem sua linguagem esmiuçada, sem receberem uma análise aprofundada de seu grau de refinamento, tão conjugável a outros campos do conhecimento, como educação artística e história.

Para que os quadrinhos sejam plenamente compreendidos - e lidos - é fundamental que se exerça uma expansão da percepção: a leitura, aqui, não se resume ao escrito, ao racional da palavra, mas engloba também o elemento sensitivo, posto que a visão é exigida de forma ampla. Em alguns casos, chega-se mesmo a romper com a estética do quadro. Em Maus, de Art Spiegelman - uma história sobre a experiência do Holocausto durante a Segunda Guerra Mundial -, o artista deixa o personagem sair do quadro, numa espécie de vazamento proposital. A situação vivida é de tal modo dramática e emocionalmente exaustiva que, em determinado instante, o personagem, levado ao limite de sua condição, estoura fisicamente o espaço. A partir da familiarização com a linguagem dos quadrinhos, é possível notar, pela extrapolação da estrutura que deveria conter o desenho, a total impossibilidade de contenção diante de um momento de fúria e, ao mesmo tempo, a superação - emocional porque espacial - desse momento.

Quadrinhos não são todos iguais. Devido ao já mencionado desconhecimento por parte de artistas, editores e livreiros, frequentemente aparecem na mesma área, o que também dificulta a compreensão das peculiaridades do gênero. Dentro do universo dos quadrinhos há tipos variados de narrativa, cada qual com características intrínsecas: de aventura, de romance, quadrinhos políticos, indie, eróticos, infanto-juvenis, quadrinhos-reportagem, biografias em quadrinhos etc. A divisão em subgêneros tende a ser consagrada; certos artistas criam apenas para determinado segmento, que, por sua vez, tem um público cativo. $O$ trabalho do italiano Milo Manara, por exemplo, é voltado para o erotismo, com um roteiro, uma abordagem e um traço muito próprios que dificilmente poderiam ser compatibilizados com aspectos dos quadrinhos infanto-juvenis.

A ignorância a respeito das particularidades do gênero engendra mal-entendidos que, infelizmente, podem vir a afastar o público. Certa vez deparei-me na livraria, na seção infantil, com o título Lost Girls, escrito por Alan Moore e ilustrado por Melinda Gebbie, editado no Brasil pela Devir. O trabalho de Melinda remete a uma estética de "contos de fadas", com traço, páginas, cores e desenhos harmoniosos, suaves. A capa, desenhada num estilo algo onírico, reforça a impressão de se tratar de um universo fantasioso, universo de princesas. O conteúdo, no entanto, traz meninas como Dorothy, de $O$ mágico de $O z$, e Alice, 


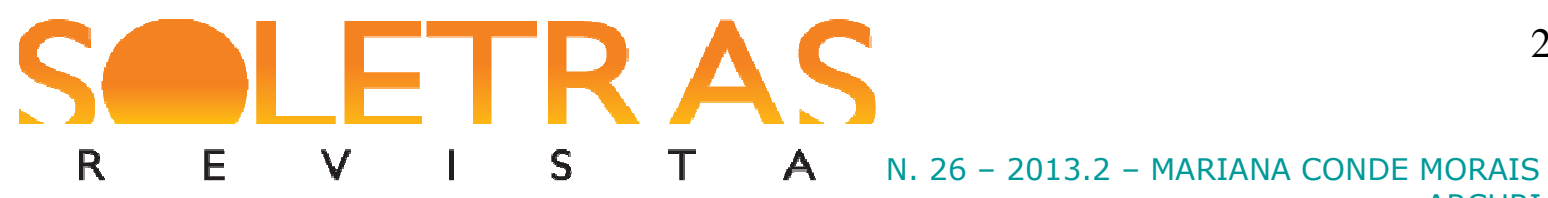

de Alice no País das Maravilhas, já crescidas - as garotas perdidas do título - e donas de extensa lista de proezas sexuais. Indo na contramão do sugerido pela ilustração da capa, o teor é altamente erótico - e certamente não deveria estar incluído na área infantil. Quem vê capa não vê coração. Embora os quadrinhos experimentem hoje um avanço expressivo no gosto do grande público, ainda se confunde o gênero como um todo com a produção voltada especificamente para o público infanto-juvenil. Quadrinhos vão além dos gibis vendidos em bancas de jornal, Turma da Mônica, Luluzinha, Tio Patinhas etc. Mesmo quando realizados com o objetivo de alcançar o público infanto-juvenil, os quadrinhos frequentemente extrapolam esse limite e atingem faixas etárias diversas e outros tipos de leitores.

Com o propósito de serem evitados equívocos, é forçoso difundir mais e mais os quadrinhos - mas não a ponto de aparar suas arestas, apagar suas variações internas. Grande parte dos artistas e mediadores sustenta que os quadrinhos devem voltar a ser tão populares quanto no passado. Os primeiros personagens de quadrinhos ganharam tamanho destaque nas páginas dominicais dos jornais que o público passou a comprar o periódico somente para ler os quadrinhos. O jornal atuava como mero veículo, a ponto de os quadrinhos, por fim, se desvencilharem desse suporte e se afirmarem como publicação independente. Conquanto alguns segmentos tenham se tornado atores do mainstream editorial - a exemplo dos comics, quadrinhos de super-heróis, massificados nos EUA graças à atuação em larga escala das editoras Marvel e DC Comics -, a procura crescente por quadrinhos não pode ser encarada como um risco à integridade artística dos mesmos.

Nesse sentido, as graphic novels mostram-se um bom exemplo de união entre sucesso comercial e inventividade estética. Criado pelo papa dos quadrinhos Will Eisner, o conceito de graphic novel buscava diferenciar o trabalho realizado por Eisner dos comics, que, embora também ocupassem espaços extensos, tinham outro valor narrativo, traço e focos de público distintos. Um comic é quadrinho, sem dúvida, mas com um conteúdo que pouco se assemelha aos das graphic novels. O que importava para Eisner era contar a história dos judeus que tinham emigrado para Nova York, expor o seu dia a dia, seus dramas cotidianos - os quadrinhos, aqui, serviriam como linguagem adequada ao relato de histórias de pessoas próximas, em meio a um ambiente e costumes familiares, a uma vizinhança partilhada. A graphic novel de Eisner estava longe dos comics e muitas vezes não tinha humor, daí ter surgido como um conceito para ajudar a entender novas formas de criação de quadrinhos. 


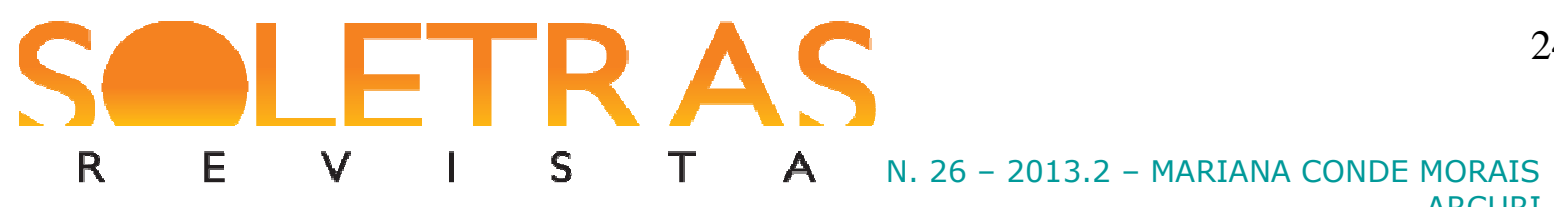

Como um teórico dos quadrinhos, Eisner formulou conceitos e noções a partir de sua compreensão dos quadrinhos como linguagem de arte.

Outra de suas notáveis definições é a que sintetiza os quadrinhos como "arte sequencial", trazendo no bojo a ideia de simultaneidade espaço-temporal, de coexistência de presente, passado e futuro. Nos quadrinhos, o passado não é só uma lembrança e o futuro é mais que uma suposição: em ambos os casos, a dinâmica da história está condicionada a um olhar em torno. Ao contrário do cinema, em que a continuidade é garantida pelo esforço de recuperação da memória do fotograma, portanto, pela representação da imagem passada, nos quadrinhos a sequência configura-se como justaposição de imagens num contínuo espaçotemporal. Prova disso é o fato de os quadrinhos usarem recursos diversos para tratarem do tempo na narrativa: por exemplo, é possível encontrar interessantes passagens de tempo simbolizadas pela paisagem vista através de uma janela - no primeiro quadro tem-se uma árvore florida, no segundo, folhas caindo, e, no terceiro, somente galhos. Com o avanço no tempo, a história se transforma - e, para que o leitor sinta essa mudança, é crucial estar criticamente preparado para o tipo de leitura estritamente ligada ao mundo dos quadrinhos. De outro modo, nada fará sentido, pois a leitura tradicional privilegia as informações contidas no texto, e não aquelas trazidas pelos demais recursos utilizados nos quadrinhos.

Há que se desviar do perigo de não contemplar a totalidade da linguagem; aqui não se trata puramente de texto acompanhado de imagens. Pelo contrário, em certas concepções mais irônicas de trabalho, o texto acintosamente desdiz a imagem, um desafio para o leitor, sobretudo o brasileiro, que não tem uma formação de leitura de imagem. No Brasil, permanece a velha dificuldade: não basta ver, é preciso estar aberto ao que se vê para que se possa, a partir disso, fazer uma leitura. Na escola, esse viés de leitura, centrado na imagem e na obra de arte, é parcamente estimulado, o que acarreta uma significativa dificuldade posterior na assimilação total do conteúdo dos quadrinhos. Para contornar o problema da leitura, investe-se cada vez mais na qualidade da apresentação dos quadrinhos, em termos estéticos e de acabamento gráfico. Se a imagem constitui um elemento narrativo insubstituível, cremos ser indispensável que ela seja o mais clara possível, que seu papel na composição da página esteja nítido. A fim de minimizar entraves na percepção, a imagem deve revelar-se ao máximo.

Esse estorvo representado pela imagem não deixa de ser um tanto surpreendente - e mesmo paradoxal - numa época que se autoproclama a "era da imagem". Embora estejamos 


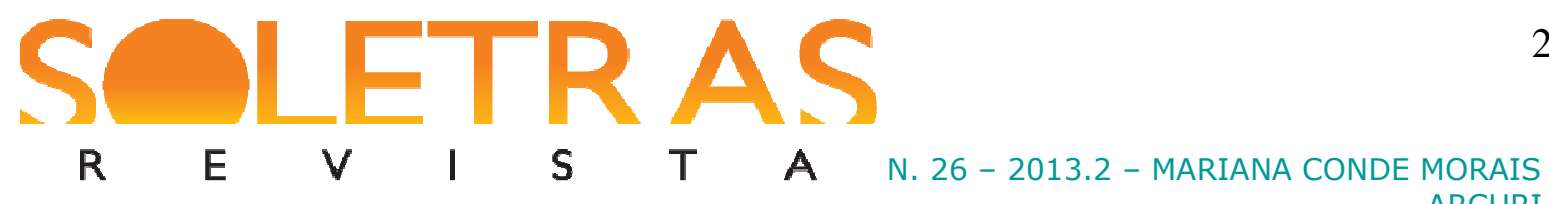

imersos em uma cultura na qual a imagem impera, poucas vezes nós a associamos a uma expressão estética independente, exceto nos casos em que ela assume intencionalmente um caráter artístico. No âmbito dos quadrinhos, o preparo para lidar com a imagem envolve também a compreensão da posição assumida por ela em cada tipo de trabalho; há quadrinhos simples com desenhos rebuscados e outros, complexos narrativamente, calcados em imagens singelas, quase primárias, de traço mais rude. A imagem ganha fôlego impulsionada pelo seguimento do roteiro, e não por se tratar de um desenho extremamente realista e detalhado. A eficácia da imagem independe de sua "beleza", mesmo porque a noção de bonito, aqui, não necessariamente é aquela atrelada ao senso comum; um traço tosco pode ser esteticamente mais instigante e repleto de significado que um mais bem-acabado.

Para se compor uma bela narrativa gráfica não é preciso ser dono de um belo traço Robert Crumb, por exemplo, apresenta uma trajetória marcante que pode ser investigada pelas mudanças em seu traço. A princípio simples, limpo e claro, seu desenho, com o passar do tempo, tornou-se mais solto, sujo, sombrio e hachurado, com riscos e traços escurecendo a imagem. Assim, dentro do universo dos quadrinhos, os artistas têm uma mobilidade muito grande, algo que se manifesta igualmente na distribuição de funções. Há profissionais que trabalham exclusivamente na elaboração de roteiros, completamente afastados do desenho; alguns, por outro lado, partem de um roteiro pronto e apenas desenham; outros, ainda, são bons quadrinistas, mas não lidam com cor e, portanto, precisam contar com a colaboração de coloristas para a valorização do traço; e há os que se ocupam de todo o processo produtivo dos quadrinhos. A criação pode ser solitária ou em conjunto, dependendo do estilo de trabalho do artista. A respeito do processo criativo desenvolvido na adaptação para quadrinhos do romance Jubiabá, de Jorge Amado (editado pelo selo Quadrinhos na Cia., da Companhia das Letras), declara o quadrinista Spacca:

[...] Essa variedade de ambientes - Salvador, o Recôncavo -, tipos malandro, prostituta, capoeirista, boxeador, artista de circo - e situações - a vida nas ruas, a greve portuária - é muito estimulante para desenhar.

Para a pesquisa, reuni primeiramente livros sobre a Bahia, de ontem e de hoje. Livros de arte, de fotografias, guias turísticos, livros sobre a Salvador de antigamente. Li e estudei Jubiabá várias vezes para conhecer a história, para ver a estrutura geral, para selecionar trechos...

[...] Depois de estudar esse material e alguns mapas de Salvador, viajei para lá e fiquei alguns dias vendo as coisas de perto e tirando fotos. [...] 


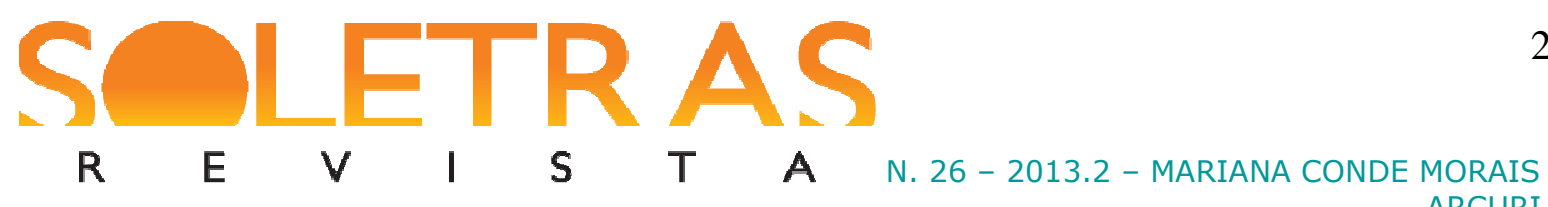

O trabalho todo levou cerca de um ano e meio. Eu trabalho sozinho. Precisei de mais ou menos seis meses para pesquisar, escrever o roteiro e desenvolver os personagens, e de um ano para desenhar e colorir os quadrinhos. (SPACCA, 2009, pp. 88-93).

O aspecto maleável dos quadrinhos pode ainda ser constatado pela presença do gênero em outros suportes, como a Internet. Certos roteiros são especialmente criados para a web, adequados a tal formato, por isso não é de causar espanto que, ao serem transpostos para o meio impresso, recortados e publicados sem qualquer tipo de adaptação, percam sua autenticidade. Se existe uma espécie de evolução nesse universo, ela é preponderantemente tecnológica. A linguagem é capaz de migrar do papel para a Internet sem prejuízo de conteúdo. Convivem, hoje, modos distintos de fazer quadrinhos: determinados artistas usam tablets para desenhar; outros permanecem fiéis ao papel; alguns criam de maneira mais artesanal, realizando aquarelas e pinturas a óleo originais que, por serem gigantescas, não sofrerão perda de nitidez e de riqueza de detalhes ao serem reduzidas a dimensões muito menores.

Independentemente da adesão ou não às novas tecnologias, há quadrinhos para todos os gostos, com diferenças imensas entre si. Alguns títulos populares são mais palatáveis, mais afeitos a um padrão comercialmente bem-sucedido, o que não impede, todavia, que haja exemplos de quadrinhos sumamente sofisticados circulando em veículos de grande alcance de público - o caso, por exemplo, das séries de Laerte publicadas na Folha de São Paulo e, em seguida, em seu blog. A linguagem permite-se uma notável multiplicidade de discursos: é possível enveredar pelo caminho do texto mais direto, brincar com o universo infantil e ser popular como a Turma da Mônica, Tintin e Astérix \& Obélix, mas também, como o maltês Joe Sacco, percorrer uma vereda mais autoral, mais inusitada. Sacco, jornalista por formação e correspondente de guerra, cobre conflitos por meio dos quadrinhos. Uma de suas empreitadas foi a cobertura, na Faixa de Gaza, da luta entre árabes e israelenses a partir de quadrinhos. $\mathrm{O}$ discurso jornalístico foi traduzido em texto e imagens, sem nunca abandonar o cunho documental e histórico.

A crescente preocupação do mercado editorial acerca do nível de palatabilidade dos quadrinhos relaciona-se intimamente ao boom do gênero ocorrido há aproximadamente seis anos; não à toa, na mesma época os quadrinhos passaram a ser incluídos nos grandes programas de compra governamental, em especial no Programa Nacional Biblioteca da Escola 


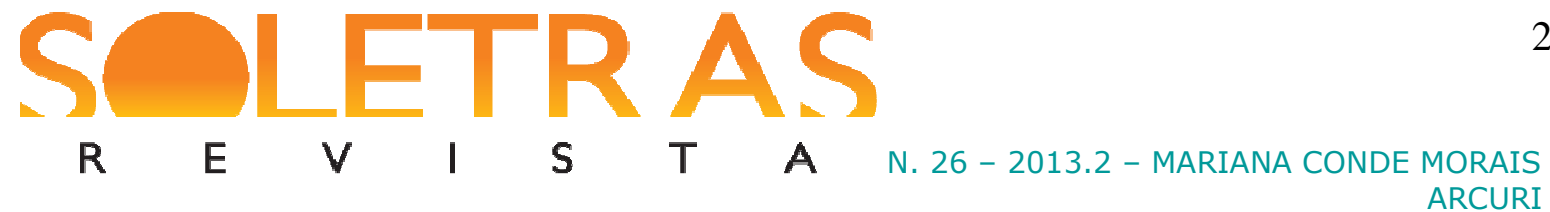

(PNBE). A respeito do programa, afirmou em entrevista Raquel Nascimento, pedagoga, professora da Creche UFF e da Prefeitura do Rio de Janeiro e ex-livreira no setor infantojuvenil:

\begin{abstract}
Acredito que haja ações isoladas, campanhas pontuais que não têm resultados expressivos. O maior avanço nesse sentido, com um viés de política pública, é o PNBE, de abrangência nacional. Tem uma boa seleção de acervo e uma grande distribuição, porém, sem professores e bibliotecários preparados, o material com grande potencial não é bem explorado, ou é, até, deixado de lado. [...] O PNBE tem uma seleção do acervo preocupada com a qualidade dos livros e a utilidade desses livros nas escolas. Não acredito que haja influência de editoras. [...] Há algumas editoras que se destacam apesar de muito do que é produzido não ser de qualidade -, muita coisa boa é lançada.

[...] Além da distribuição de acervo de qualidade (nas escolas e nas bibliotecas públicas), a formação dos professores das séries iniciais e de Língua Portuguesa é importantíssima, já que, muitas vezes, eles próprios não são leitores. Acredito que as políticas públicas no sentido da formação de leitores no Brasil devem ir além da distribuição de livros e ter seu alicerce na gestão das instituições e na formação e acompanhamento dos profissionais que irão lidar com esse acervo e efetivamente se tornar mediadores na formação de leitores (NASCIMENTO, 2011).
\end{abstract}

A partir de 2006 (ano da entrada dos quadrinhos no programa), cresceu o interesse das editoras brasileiras em se adaptarem a essa nova demanda inserida no edital. Como os valores envolvidos nas vendas são vultosos, muitas editoras apressaram-se em adentrar, de supetão, o universo dos quadrinhos - e, nesse ímpeto, frequentemente cometeu-se o clássico erro de misturar joio e trigo.

Tal engano talvez advenha da crença um tanto ingênua, por parte do mercado, de que os quadrinhos, ao trazerem adaptações literárias, vão simplificar a literatura e torná-la mais "acessível” à sensibilidade do público infanto-juvenil médio. Na contramão de tal convicção, muitos artistas defendem a manutenção da sofisticação da literatura e, ao mesmo tempo, a independência dos quadrinhos. A esse respeito, Guazzelli, autor da adaptação do conto Demônios, de Aluísio Azevedo (lançada na série Clássicos em HQ, da editora Peirópolis), relata sua experiência com a literatura e como, trabalhando com quadrinhos, ela se lhe afigura esteticamente inspiradora:

A literatura foi a grande parceira do guri esquisito que fui. Foi meu irmão mais velho que me apresentou essa pequena relíquia: o conto Demônios. Ele 


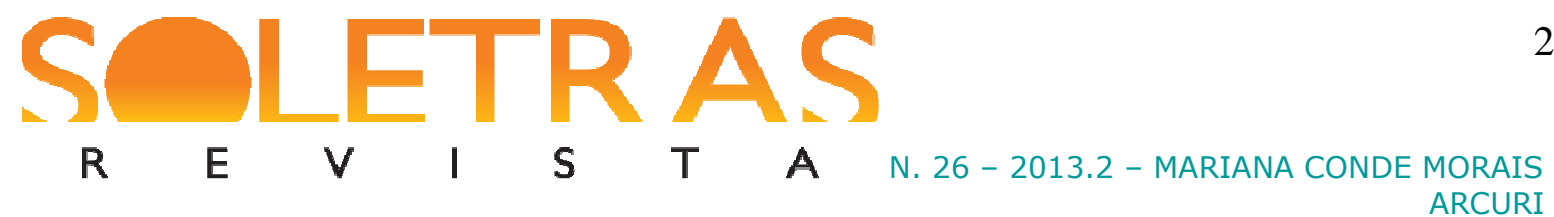

chamou minha atenção justamente para o enorme potencial imagético desse texto numa época em que eu ainda não fazia quadrinhos, mas essa impressão ficou gravada no meu inconsciente. [...] foi numa ambientação de sonho que procurei construir minha tradução. Deixei que a própria estrutura dos quadrinhos fosse contaminada pelo caos da narrativa [...] (GUAZZELLI, 2010, 53). (Grifo meu).

Se um quadrinista cede ao impulso de simplificação, geralmente finda por produzir uma péssima adaptação - o que, aliás, vem ocorrendo amiúde nestes últimos tempos. Boas adaptações costumam construir-se com base na tradução (para usar o termo cunhado por Guazzelli), na revisitação, não apenas do enredo, mas também do estilo do autor, da atmosfera por ele criada, num diálogo inquieto e produtivo entre o original literário e os quadrinhos. Longe de aceitarem passivamente a mera transposição do plot para texto e imagem, os quadrinhos devem, acima de tudo, oferecer uma versão autônoma e inventiva a partir da estrutura original. No texto sugestivamente intitulado "Machado revisitado", prefácio à adaptação de Memórias póstumas de Brás Cubas realizada por João Batista Melado e Wellington Srbek, e editada pela Desiderata (selo da Nova Fronteira / Ediouro), Moacyr Scliar argumenta, perspicaz:

Olhando a irmã que lê, Alice, aquela do País das Maravilhas, pergunta-se: "Para que serve um livro sem figuras?" Uma indagação que muitos se fizeram, e que, ao longo do tempo, motivou artistas de todo o mundo a usar seu talento na ilustração (Sir John Tenniel no próprio Alice no País das Maravilhas, Belmonte em várias obras de Lobato) e não só de livros infantis: Dom Quixote foi soberbamente ilustrado por Gustave Doré. Há um fundamento, psicológico até, para isso: todo leitor traduz, quase que automaticamente, as palavras que está lendo no texto em imagens. Visualização é parte da fantasia, como mostram os sonhos e os devaneios. Mas os grandes ilustradores vão mais além e, a partir da tarefa que lhes é delegada, criam obras de arte, como demonstram os exemplos citados. Um passo mais adiante, e as ilustrações adquirem vida própria: passam a representar uma interação dinâmica e fecunda do artista com a palavra impressa (SCLIAR, 2010, p. 5).

Uma adaptação realizada a contento deve partir de um roteiro que privilegie o estilo de narrativa dos quadrinhos, não somente os elementos narrativos tipicamente literários encontrados no original, ainda que se trate de pontos altos na obra que se pretende adaptar. Como, por exemplo, adaptar de modo estrito uma metáfora? Figuras de linguagem funcionam de modos diversos na literatura e nos quadrinhos. 


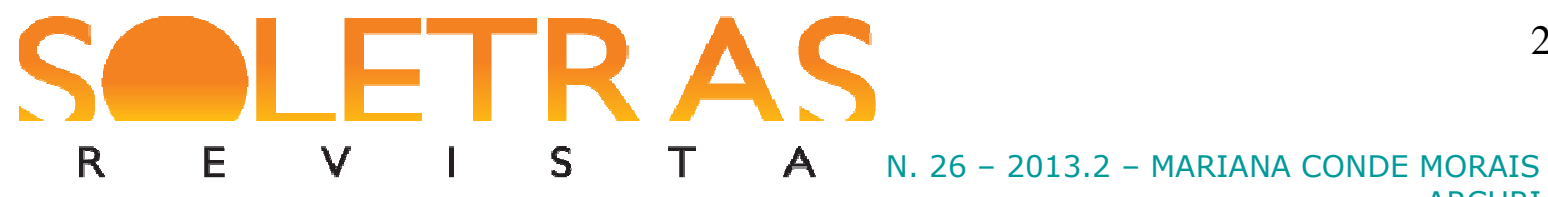

Essa tentativa de tosca simplificação por vezes acaba sendo rejeitada pelo público infanto-juvenil, que, diante de uma narrativa discursiva e esteticamente mal resolvida, percebe o engodo representado pela solução pobre presente na junção de meia página de texto e um desenho, e, por conseguinte, tende a perder o interesse. Raquel Nascimento dá o seguinte testemunho no que concerne a certa parcela da produção editorial voltada para o público infanto-juvenil:

Acredito que o mercado editorial produz muitos livros infantis; grande parte é "infantilizadora", ou com pobreza de características que o tornem um livro de qualidade (texto pobre, ilustração pouco atrativa etc.). Os especialistas e os prêmios de literatura infantil e juvenil, de certa forma, apontam o que de qualidade foi produzido. Nesse sentido, a qualidade transpõe as barreiras do que é infantil, juvenil ou adulto - é o que constitui a obra como Literatura. [...] A "leitura ideal" é aquela da qual a criança gosta. Mas para a criança e o jovem identificarem aquilo de que eles gostam (ou não gostam) um grande número de possibilidades de gênero e acervo deve estar à disposição desse público. Dessa forma, os mediadores da leitura (pais, professores e amigos) ajudam os leitores em formação a encontrar sua "leitura ideal" (NASCIMENTO, 2011).

Há no mercado inúmeras adaptações literárias em quadrinhos em que o desenho não conta a história, mas apenas ilustra o texto contido no balão - algo que vai de encontro à linguagem dos quadrinhos, em que o desenho narra a história e o balão traz a fala do personagem, não um inserto de texto. A narração não depende, absolutamente, do conteúdo textual do balão; a narração frequentemente vem na própria imagem, que, soberana, se deve bastar. A "voz" do narrador, quando textual, não é enquadrada pelo balão; existem alguns recursos, como a presença de narrações no pé da página ou em pergaminhos desenhados, que permitem a transmissão dessa "voz" sem a necessidade de apelo ao balão. Trata-se de soluções engenhosas que seduzem o leitor e o aproximam ainda mais desse universo.

Para que essas e outras soluções possam ser apreciadas em toda a sua extensão e complexidade, é essencial que haja uma abertura para se compreender a fundo a linguagem dos quadrinhos. Pesquisas cuidadosas, livres de preconceitos, ainda são escassas - para não dizer praticamente inexistentes -, e movimentos nesse sentido são lentos e intermitentes. Análises críticas, longe de (in) validarem a pertinência dessa nova linguagem, contribuiriam significativamente para que a potência criativa dos quadrinhos fosse plenamente entendida e estimada. 


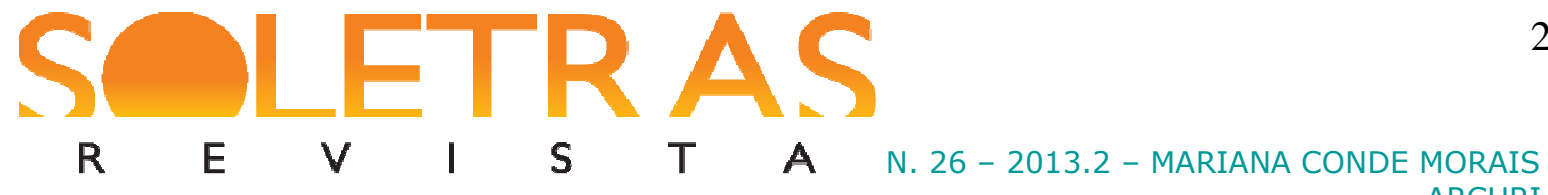

A escola brasileira de quadrinhos conseguiu distanciar-se dos modelos consagrados, fundadores, o padrão franco-belga e o americano, para tecer sua originalidade, qualidade e inventividade. A escola franco-belga sempre teve como característica marcante certa independência em relação ao mercado editorial, mesmo quanto ao modo de produção dos quadrinhos. Como os quadrinhos franco-belgas têm uma trajetória há décadas consolidada, muitos impasses mercadológicos já foram superados: a questão da distribuição de material e a política de vendas há anos estão acertadas.

No universo franco-belga, as editoras menores, mais distantes do mainstream, ocupamse do gênero, cujo apelo é mais centrado na valorização do traço do artista e no caráter autoral da obra, sem se ater a fórmulas - o contrário, por exemplo, do que habitualmente ocorre nos EUA, em que a supremacia do mercado obriga o quadrinista a nivelar e padronizar seu estilo. A fim de se encaixar na engrenagem de uma das "grandes" do gênero - Marvel ou DC Comics -, o artista norte-americano é levado a abandonar as peculiaridades de seu traço algo que também acontece no Brasil, como atesta o exemplo fornecido pelos estúdios de Mauricio de Sousa, cujo esquema de trabalho orienta-se pela produção em larga escala. Artistas famosos, de traço extremamente característico, devem deixar de lado seu estilo a fim de incorporarem o modelo de criação estabelecido para a imensa equipe que trabalha nos estúdios: roteiristas, desenhistas, coloristas, designers de tipos. Não se trata absolutamente de negar a qualidade das histórias da Turma da Mônica, apenas de assinalar o modo de produção que a condiciona.

No entanto, além do padrão de criação espelhado no modelo norte-americano, é possível verificar no Brasil a existência, fortalecida nos últimos anos, de esquemas mais livres: esse é o caso dos coletivos, agrupamentos de artistas cuja finalidade é dividir - portanto, baratear - os custos de produção de um álbum independente e realizar publicações-panorama compostas de várias histórias, como fazem os cariocas da revista Beleléu e os capixabas da revista Prego. No Brasil de hoje não é mais cabível falar em "estilo nacional" - os traços são plurais, regionais, e constantemente dialogam entre si e com outras escolas do mundo. Diversidade e riqueza não faltam nessa linguagem; é necessário, pois, contemplá-la mais detidamente.

\section{Referências bibliográficas:}

COSTA, Flávio Moreira da. Rima e solução. In: MOON, Fábio; BÁ, Gabriel. O alienista. Rio de Janeiro: Agir, 2007. 


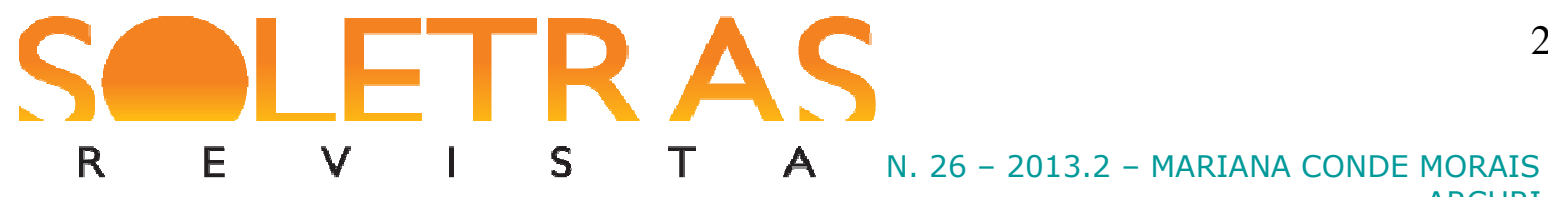

GUAZZELLI. Demônios. São Paulo: Peirópolis, 2010.

. O pagador de promessas. Rio de Janeiro: Agir, 2009.

MELADO, João Batista; SRBEK, Wellington. Memórias póstumas de Brás Cubas. Rio de Janeiro: Desiderata, 2010.

MONTEIRO, Alzira Valéria. Entrevista. Concedida em 21 fev. 2011.

MOON, Fábio; BÁ, Gabriel. O alienista. Rio de Janeiro: Agir, 2007.

NASCIMENTO, Raquel. Entrevista. Concedida em fev. 2011.

SCLIAR, Moacyr. Machado revisitado. In: MELADO, João Batista; SRBEK, Wellington. Memórias póstumas de Brás Cubas. Rio de Janeiro: Desiderata, 2010.

SPACCA. Jubiabá. São Paulo: Quadrinhos na Cia., 2010.

VASQUES, Edgar; BRAGA, Flávio. Triste fim de Policarpo Quaresma. Rio de Janeiro: Desiderata, 2010.

\section{El cómic, hoy}

Resumen: Para que el público perciba el cómic como estética independiente, con ideas y códigos peculiares, y pueda familiarizarse con él, es esencial que el género sea visto como un objeto de lectura en sí mismo, y no una especie de puente para llegar a un otro nivel supuestamente más sofisticado de lectura. Este trabajo pretende mostrar cómo, al definirse como lenguaje libre, el cómic encuentra en su propia constitución su refinamiento. Con el objetivo de difundir la gramática particular del cómic, urge formar lectores acostumbrados a este género. La ruta, sin embargo, es tortuosa. Casi no hay producción académica sobre el tema, entonces usamos la propia historia del cómic, testimonios de profesionales del medio, para formar una base teórica coherente. Rara vez el cómic se aprende en la escuela, y cuando se aprende, por lo general aparece en libros didácticos como paradigma de error, desviación de las normas de la lengua. Además, a veces el cómic hace el papel de mero adorno ilustrativo, sin escrudiñarse su lenguaje, sin recibir un análisis denso de su grado de sofisticación, conjugável a otros campos de conocimiento. Este trabajo se erige como un intento para solucionar esto.

Palabras-clave: Cómic. Literatura contemporánea. Edición. Formación de lectores.

Recebido em: 02 de outubro de 2013.

Aprovado em: 10 de novembro de 2013. 